\title{
Short-term ECG recordings for heart rate assessment in patients with chronic atrial fibrillation
}

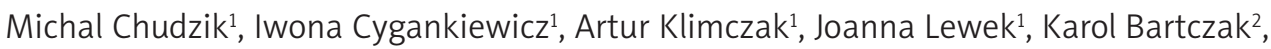
Jerzy K. Wranicz ${ }^{1}$

${ }^{1}$ Department of Electrocardiology, Medical University of Lodz, Poland
${ }^{2}$ Department of Cardiosurgery, Medical University of Lodz, Poland

Submitted: 27 February 2011

Accepted: 11 March 2012

Arch Med Sci 2014; 10, 4: 676-683

DOI: 10.5114 /aoms.2014.44859

Copyright (c) 2014 Termedia \& Banach
Corresponding author:

Michal Chudzik MD

Department

of Electrocardiology

Medical University of Lodz

$1 / 3$ Sterlinga St

91-425 Lodz, Poland

Phone: +48691941814

E-mail: michalchudzik@wp.pl

\begin{abstract}
Introduction: There is no consensus on the length of ECG tracing that should be recorded to represent adequate rate control in patients with atrial fibrillation (AFib). The purpose of the study was to examine whether heart rate measurements based on short-term ECGs recorded at different periods of the day may correspond to the mean heart rate and rate irregularity analyzed from standard 24-hour Holter monitoring.

Material and methods: The study enrolled 50 consecutive patients with chronic AFib who underwent 24-hour Holter monitoring. Mean heart rate $(\mathrm{mHR})$ and the coefficient of irregularity $(\mathrm{Cl})$ were assessed from 5- and 60-minute intervals of Holter recordings in different periods of the day.

Results: The highest correlation in mean heart rate interval within $24 \mathrm{~h}$ was found during a 6-hour sample and in the periods $11.00 \mathrm{AM}-12.00 \mathrm{PM}$, 12 PM-1.00 PM, and 1.00 PM-2.00 PM. With respect to irregularity, only the $\mathrm{Cl}$ measurements based on a 6-hour interval (7.00 AM-1.00 AM) show a correlation $>0.08$ compared to data from the 24 -hour recording.

Conclusions: Only long-term (6-hour) recordings provide a high correlation within $24 \mathrm{~h}$ in mean heart rate interval and coefficient of irregularity. It seems that the mean heart rate interval in 1-hour periods between $11 \mathrm{AM}$ and $2 \mathrm{PM}$ might be predictive for 24-hour data. Short time recordings of the coefficient of irregularity of heart rate in AFib patients at this moment are not useful in clinical practice for long-term prognosis of ventricular irregularity.
\end{abstract}

Key words: atrial fibrillation, ventricular rate control, rate irregularity.

\section{Introduction}

The majority of symptoms in patients with atrial fibrillation (AFib) are caused by a rapid and/or irregular ventricular rate [1, 2]. Even in asymptomatic patients, uncontrolled ventricular heart rate may lead to the development of tachycardia-mediated cardiomyopathy [3-6]. This is why the optimal control of ventricular rate during AFib has gained considerable clinical importance. Recent publications of randomized trials have shown that strategies of rate control and sinus rhythm maintenance are equivalent, as measured by various end points [7-11]. Unfortunately, the definition of adequate rate control is somewhat arbitrary. As it was underlined, according to recent ESC/AHA/ACC guidelines, criteria for rate control may vary with respect to an individual patient [12]. It is worth emphasizing that even in patients with an acceptable heart rate 
range, considered therefore as "well-controlled AFib," irregularity of the ventricular response may contribute to worsening of quality of life, clinical symptoms, and/or development of tachycardiomyopathy. Electrocardiography remains the gold standard means of monitoring ventricular rates in $\mathrm{AF}$, but all three modes of data acquisition, namely static 12-lead ECG, 24-hour Holter monitoring, and exercise tolerance testing, need to be used for a thorough and complete assessment. Nevertheless, Holter monitoring is frequently considered as a costly procedure, and patients' compliance may be low. As cost-effectiveness plays a progressively larger role in patients' management, it seems reasonable to limit the number of clinical visits and additional examinations $[13,14]$. To date, there is no consensus on how to define the proper rate control and the length of ECG tracing that should be recorded.

The purpose of the study was to examine whether heart rate measurements based on shortterm ECG recorded at different periods of the day may represent mean heart rate and rate irregularity obtained from standard 24-hour Holter monitoring.

\section{Material and methods}

\section{Study population}

A total of 50 ambulatory patients (22 males and 28 females, mean age $72 \pm 6$ years) with chronic AFib were enrolled in the study. In all the patients, 15 min of resting in a supine position and ambulatory Holter recording initiated immediately after a resting period were performed during clinical visits. Holter recordings were performed with Medilog FD5 Oxford recorders and typical CS2, CM5, and IS leads. The recordings were analyzed using the Oxford Medilog Excel 2 system. Both automatic and manual analyses were performed. After the recordings had been edited and visually verified, the mean heart rate interval (mHR) and coefficient of irregularity $(\mathrm{Cl})$ were assessed. Coefficient of irregularity was defined according to Greenhut et al. [15] as a quotient of standard deviation of all normal-to-normal cycles (SDNN) and mean heart rate (mHR). These parameters ( $\mathrm{mHR}$ and $\mathrm{Cl}$ ) were assessed from 24-hour recording and then were compared with short-term ECG samples. The following shortand long-term samples were considered: 5-minute period: 8.00 AM-8.05 AM, 9.00 AM-9.05 AM, 10.00 AM-10.05 AM, 11.00 AM-11.05 AM, 12.00 PM-12.05 PM, 1.00 PM-1.05 PM; 1-hour period: $8.00 \mathrm{AM}-9.00 \mathrm{AM}, 9.00 \mathrm{AM}-10.00 \mathrm{AM}$, 10.00 AM-11.00 AM, 11.00 AM-12.00 PM, 12.00 PM-1.00 PM, 1.00 PM-2.00 PM; and 6-hour period $7.00 \mathrm{AM}-1.00 \mathrm{PM}$.
These intervals and time periods were arbitrarily chosen by the authors as the most similar to physicians' working period of the day. All patients during the study were under one physician follow-up with medications taken during the same period of the day. Heart rate in all patients was defined as optimal if the ventricular rate during 30 -second pulse examination in the resting period was below 100 bpm.

The study protocol was approved by the Institutional Investigation Committee, and all patients signed informed consent.

\section{Statistical analysis}

Some missing values in the data set were filled in using the regression imputation method. Numeric variables are expressed as mean \pm standard deviation (SD). Minimum, maximum, median and IQR (interquartile range - Q25-Q75) are also presented. For categorical variables the number of observations ( $n$ ) and fraction (\%) were calculated.

Normality was tested using the Shapiro-Wilk test for normality. Due to the lack of normality, Friedman's test with post-hoc analysis was used to compare the studied variables. Spearman's rank correlation coefficients were calculated to assess the correlation between 24-hour data and the results from shorter measurement periods.

The results were considered significant for $p<0.05$. All analyses were performed using Statistica PL 9.0 software.

\section{Results}

The final analysis included 50 patients ( 22 males and 28 females), aged from 59 to 80 years (mean $71 \pm 7$ years). All the patients presented with chronic AFib with an average duration of $28 \pm 11$ months. Coronary artery disease and hypertension were the most frequently coexisting underlying diseases, whereas valvular heart disease was present in only 2 patients. The left ventricle ejection fraction assessed by echocardiographic examination ranged from $32 \%$ to $78 \%$ (mean $61 \%)$. The majority of patients (41 (82\%)) presented NYHA class I or II symptoms. Most of them (96\%) were treated with $\beta$-blockers. Detailed clinical data and medications of studied patients are shown in Table I.

\section{Heart rate measurements}

The mean, median, minimum, maximum and standard deviation of heart rate intervals are displayed in Table II. The mean interval from 24-hour Holter recordings in all examined patients was 0.801 $\pm 0.134 \mathrm{~ms}$. The shortest interval assessed from 60-minute samples was found between 1.00 PM and 2.00 PM (0.698 $\pm 0.127 \mathrm{~ms})$, whereas the lon- 
Table I. Clinical characteristics of studied population

\begin{tabular}{|lc|}
\hline Clinical variables & $\begin{array}{c}\text { Patients }(N=50) \\
n(\%) / \text { mean } \pm \text { SD }\end{array}$ \\
\hline Gender (males) & $22(44)$ \\
\hline Age [years] & $72 \pm 7$ \\
\hline Coronary artery disease & $22(44)$ \\
\hline Past myocardial infarction & $12(24)$ \\
\hline NYHA class I/II & $41(82)$ \\
\hline NYHA class III & $9(18)$ \\
\hline Hypertension & $20(40)$ \\
\hline Diabetes & $5(10)$ \\
\hline Valvular heart disease & $2(4)$ \\
\hline Dilated cardiomyopathy & $2(4)$ \\
\hline Ejection fraction [\%] & $61 \pm 14$ \\
\hline Medication: & $28(56)$ \\
\hline Digitalis & $48(96)$ \\
\hline B-Blockers & $14(28)$ \\
\hline Calcium channel antagonists & \\
\hline
\end{tabular}

NYHA - New York Heart Association, SD - standard deviation

gest interval was observed between $10.00 \mathrm{AM}$ and $11.00 \mathrm{AM}(0.765 \pm 0.186 \mathrm{~ms})$.

The mean $\mathrm{Cl}$ during $24 \mathrm{~h}$ was $0.38 \pm 0.64$. The highest irregularity was found during 6-hour recordings between $7.00 \mathrm{AM}$ and 1.00 PM - 0.51 \pm 1.49 . All data of $\mathrm{Cl}$ are shown in Table III.

\section{Short-term vs. long-term monitoring} of heart rate

The comparisons of the mean heart rate interval and $\mathrm{Cl}$ assessed during examined periods of 5-minute, 60-minute and 6-hour recordings to 24hour monitoring data are summarized in Tables IV and $\mathrm{V}$. The mean value of HR during 5-minute samples recorded between 10.00 AM and 10.05 AM as well as $11.00 \mathrm{AM}$ and $11.05 \mathrm{AM}$ was similar to 24-hour mHR. The coefficient of variation from all samples retrieved from 24-hour monitoring was significantly different from the overall long-term irregularity.

The correlation between 24-hour data and other examined periods in mean heart rate interval and $\mathrm{Cl}$ parameters is shown in Tables $\mathrm{VI}$ and VII. All values of mean heart rate interval were statistically significant; however, the highest correlation with long-term recordings was found for the 6-hour sample (7.00 AM-1.00 PM) $-R=0.794$ for $\mathrm{mHR}$ and $R=0.834$ for $\mathrm{Cl}$. Correlations $R>0.7$ in mean heart rate interval between the 24-hour period and 1-hour recording at 11.00 AM-12.00 PM, 12.00 PM-1.00 PM, and 1.00 PM-2.00 PM were found. In short-term (5-minute) recordings, the correlation was always $R<0.7$ in mean HR as well as in coefficient of irregularity.

Figures 1 and 2 show the highest correlations between mean 24-hour heart rate interval in the following periods: $1.00 \mathrm{PM}-2.00 \mathrm{PM}$ and $7.00 \mathrm{AM}$ -1.00 PM.

\section{Discussion}

Our study showed that data retrieved from short-term ECG recordings obtained either during follow-up visits or in the morning period of Holter monitoring are useful in the assessment of proper heart rate control. These short-term ECG inter-

Table II. Values of mean, median, minimum, maximum intervals of heart rate, standard deviation and interquartile range (Q25-Q75) for 50 patients with atrial fibrillation

\begin{tabular}{|lccccc|}
\hline Mean HR & Mean \pm SD & Median & IQR (Q25-Q75) & Min. & Max. \\
\hline$-24 \mathrm{~h}$ & $0.8013 \pm 0.1340$ & 0.7890 & $0.7012-0.8659$ & 0.5965 & 1.0880 \\
\hline 8.00 AM - 9.00 AM & $0.7162 \pm 0.2293$ & 0.6859 & $0.5856-0.7445$ & 0.4534 & 2.0201 \\
\hline $9.00 \mathrm{AM}-10.00 \mathrm{AM}$ & $0.7134 \pm 0.1228$ & 0.7092 & $0.6342-0.7920$ & 0.5037 & 0.9595 \\
\hline $10.00 \mathrm{AM}-11.00 \mathrm{AM}$ & $0.7654 \pm 0.1855$ & 0.7350 & $0.6408-0.8890$ & 0.4057 & 1.3827 \\
\hline $11.00 \mathrm{AM}-12.00 \mathrm{PM}$ & $0.7610 \pm 0.2722$ & 0.7082 & $0.6116-0.8535$ & 0.3928 & 2.1472 \\
\hline $12.00 \mathrm{PM}-1.00 \mathrm{PM}$ & $0.7283 \pm 0.1690$ & 0.6967 & $0.6244-0.8010$ & 0.4072 & 1.2321 \\
\hline $1.00 \mathrm{PM}-2.00 \mathrm{PM}$ & $0.6977 \pm 0.1272$ & 0.6761 & $0.6215-0.7354$ & 0.4844 & 1.0921 \\
\hline $8.00 \mathrm{AM}-8.05 \mathrm{AM}$ & $0.7228 \pm 0.2298$ & 0.6905 & $0.6315-0.7566$ & 0.4338 & 1.9539 \\
\hline 9.00 AM - 9.05 AM & $0.7176 \pm 0.1201$ & 0.7166 & $0.6541-0.7537$ & 0.4773 & 1.0944 \\
\hline $10.00 \mathrm{AM}-10.05 \mathrm{AM}$ & $0.7428 \pm 0.1308$ & 0.7356 & $0.6436-0.8241$ & 0.5197 & 1.0414 \\
\hline $11.00 \mathrm{AM}-11.05 \mathrm{AM}$ & $0.7996 \pm 0.3221$ & 0.7304 & $0.6352-0.8562$ & 0.3995 & 2.1494 \\
\hline $12.00 \mathrm{PM}-12.05 \mathrm{PM}$ & $0.7685 \pm 0.3008$ & 0.7073 & $0.6203-0.8177$ & 0.3943 & 2.3656 \\
\hline $1.00 \mathrm{PM}-1.05 \mathrm{PM}$ & $0.7230 \pm 0.1847$ & 0.7210 & $0.6090-0.7485$ & 0.4621 & 1.6344 \\
\hline $7.00 \mathrm{AM}-1.00 \mathrm{PM}$ & $0.7257 \pm 0.1400$ & 0.6916 & $0.6343-0.8055$ & 0.4664 & 1.0362 \\
\hline
\end{tabular}

$H R$ - heart rate, min. - minimum, max. - maximum, SD - standard deviation 
Table III. Values of mean, median, minimum, maximum, standard deviation and interquartile range (Q25-Q75) of the coefficient of irregularity for 50 patients with atrial fibrillation

\begin{tabular}{|lccccc|}
\hline $\mathrm{Cl}$ & Mean \pm SD & Median & IQR (Q25-Q75) & Min. & Max. \\
\hline $24 \mathrm{~h}$ & $0.3824 \pm 0.6380$ & 0.2875 & $0.2242-0.3322$ & 0.1130 & 4.7392 \\
\hline 8.00 AM - 9.00 AM & $0.2342 \pm 0.0553$ & 0.2360 & $0.2151-0.2656$ & 0.0811 & 0.3431 \\
\hline 9.00 AM - 10.00 AM & $0.2334 \pm 0.0583$ & 0.2396 & $0.2128-0.2734$ & 0.0777 & 0.3190 \\
\hline $10.00 \mathrm{AM}-11.00 \mathrm{AM}$ & $0.3208 \pm 0.2908$ & 0.2324 & $0.1735-0.2842$ & 0.0781 & 1.4327 \\
\hline $11.00 \mathrm{AM}-12.00 \mathrm{PM}$ & $0.2664 \pm 0.1985$ & 0.2351 & $0.1821-0.2713$ & 0.0277 & 1.2202 \\
\hline $12.00 \mathrm{PM}-1.00 \mathrm{PM}$ & $0.2462 \pm 0.1683$ & 0.2116 & $0.1872-0.2614$ & 0.0627 & 1.1554 \\
\hline $1.00 \mathrm{PM}-2.00 \mathrm{PM}$ & $0.2220 \pm 0.1107$ & 0.2088 & $0.1776-0.2666$ & 0.0457 & 0.8288 \\
\hline 8.00 AM - 8.05 AM & $0.2116 \pm 0.0638$ & 0.2128 & $0.1944-0.2380$ & 0.0130 & 0.3336 \\
\hline 9.00 AM - 9.05 AM & $0.2191 \pm 0.0610$ & 0.2212 & $0.2115-0.2490$ & 0.0217 & 0.3574 \\
\hline $10.00 \mathrm{AM}-10.05 \mathrm{AM}$ & $0.2663 \pm 0.3144$ & 0.2229 & $0.1679-0.2637$ & 0.0803 & 2.2993 \\
\hline $11.00 \mathrm{AM}-11.05 \mathrm{AM}$ & $0.2374 \pm 0.1823$ & 0.2037 & $0.1724-0.2465$ & 0.0253 & 1.0608 \\
\hline $12.00 \mathrm{PM}-12.05 \mathrm{PM}$ & $0.2248 \pm 0.1384$ & 0.1983 & $0.1788-0.2371$ & 0.0255 & 0.8584 \\
\hline $1.00 \mathrm{PM}-1.05 \mathrm{PM}$ & $0.2095 \pm 0.0949$ & 0.2073 & $0.1777-0.2442$ & 0.0110 & 0.7110 \\
\hline 7.00 AM - 1.00 PM & $0.5142 \pm 1.4979$ & 0.2686 & $0.2113-0.3006$ & 0.1376 & 10.8111 \\
\hline
\end{tabular}

$\mathrm{Cl}$-coefficient of irregularity, min. - minimum, max. - maximum, SD - standard deviation

Table IV. Comparisons of the mean heart rate interval assessed during 5-minute, 60-minute and 6 -hour recordings examined at different times of the day to 24-hour monitoring

\begin{tabular}{|c|c|}
\hline Comparisons* & Value of $p$ \\
\hline Friedman's test & $<0.001$ \\
\hline $\begin{array}{l}\text { Mean HR - } 24 \text { h \& Mean HR - } \\
8.00 \mathrm{AM}-9.00 \mathrm{AM}\end{array}$ & $<0.05$ \\
\hline $\begin{array}{l}\text { Mean HR - 24 h \& Mean HR - } \\
9.00 \mathrm{AM}-10.00 \mathrm{AM}\end{array}$ & $<0.05$ \\
\hline $\begin{array}{l}\text { Mean HR - } 24 \text { h \& Mean HR - } \\
\text { 10.00 AM - 11.00 AM }\end{array}$ & $<0.05$ \\
\hline $\begin{array}{l}\text { Mean HR }-24 \mathrm{~h} \& \text { Mean HR - } \\
11.00 \mathrm{AM}-12.00 \mathrm{PM}\end{array}$ & $<0.05$ \\
\hline $\begin{array}{l}\text { Mean HR - } 24 \text { h \& Mean HR - } \\
12.00 \text { PM - } 1.00 \text { PM }\end{array}$ & $<0.05$ \\
\hline $\begin{array}{l}\text { Mean HR }-24 \text { h \& Mean HR - } \\
1.00 \text { PM - 2.00 PM }\end{array}$ & $<0.05$ \\
\hline $\begin{array}{l}\text { Mean HR }-24 \mathrm{~h} \text { \& Mean HR - } \\
8.00 \mathrm{AM}-8.05 \mathrm{AM}\end{array}$ & $<0.05$ \\
\hline $\begin{array}{l}\text { Mean HR - } 24 \text { h \& Mean HR - } \\
9.00 \text { AM - } 9.05 \text { AM }\end{array}$ & $<0.05$ \\
\hline $\begin{array}{l}\text { Mean HR - } 24 \mathrm{~h} \& \text { Mean HR - } \\
10.00 \mathrm{AM}-10.05 \mathrm{AM}\end{array}$ & NS \\
\hline $\begin{array}{l}\text { Mean HR }-24 \mathrm{~h} \& \text { Mean HR - } \\
11.00 \mathrm{AM}-11.05 \mathrm{AM}\end{array}$ & NS \\
\hline $\begin{array}{l}\text { Mean HR - 24 h \& Mean HR - } \\
12.00 \text { PM - 12.05 PM }\end{array}$ & $<0.05$ \\
\hline $\begin{array}{l}\text { Mean HR - } 24 \text { h \& Mean HR - } \\
1.00 \text { PM - 1.05 PM }\end{array}$ & $<0.05$ \\
\hline $\begin{array}{l}\text { Mean HR - 24 h \& Mean HR - } \\
7.00 \mathrm{AM}-1.00 \mathrm{PM}\end{array}$ & $<0.05$ \\
\hline
\end{tabular}

Table V. Comparisons of coefficient of irregularity assessed during examined periods of $5 \mathrm{~min}, 60 \mathrm{~min}$ and $6 \mathrm{~h}$ at different times of the day to 24-hour monitoring

\begin{tabular}{|c|c|}
\hline Comparisons* & Value of $p$ \\
\hline Friedman's test & $<0.001$ \\
\hline $\mathrm{Cl}-24 \mathrm{~h} \& \mathrm{Cl}-8.00 \mathrm{AM}-9.00 \mathrm{AM}$ & $<0.05$ \\
\hline $\mathrm{Cl}-24 \mathrm{~h} \& \mathrm{Cl}-9.00 \mathrm{AM}-10.00 \mathrm{AM}$ & $<0.05$ \\
\hline $\mathrm{Cl}-24 \mathrm{~h} \& \mathrm{Cl}-10.00 \mathrm{AM}-11.00 \mathrm{AM}$ & $<0.05$ \\
\hline $\mathrm{Cl}-24 \mathrm{~h} \& \mathrm{Cl}-11.00 \mathrm{AM}-12.00 \mathrm{PM}$ & $<0.05$ \\
\hline $\mathrm{Cl}-24 \mathrm{~h} \& \mathrm{Cl}-12.00 \mathrm{PM}-1.00 \mathrm{PM}$ & $<0.05$ \\
\hline $\mathrm{Cl}-24 \mathrm{~h} \& \mathrm{Cl}-1.00 \mathrm{PM}-2.00 \mathrm{PM}$ & $<0.05$ \\
\hline $\mathrm{Cl}-24 \mathrm{~h} \& \mathrm{Cl}-8.00 \mathrm{AM}-8.05 \mathrm{AM}$ & $<0.05$ \\
\hline $\mathrm{Cl}-24 \mathrm{~h} \& \mathrm{Cl}-9.00 \mathrm{AM}-9.05 \mathrm{AM}$ & $<0.05$ \\
\hline $\mathrm{Cl}-24 \mathrm{~h} \mathrm{\&} \mathrm{Cl}-10.00 \mathrm{AM}-10.05 \mathrm{AM}$ & $<0.05$ \\
\hline $\mathrm{Cl}-24 \mathrm{~h} \& \mathrm{Cl}-11.00 \mathrm{AM}-11.05 \mathrm{AM}$ & $<0.05$ \\
\hline $\mathrm{Cl}-24 \mathrm{~h} \& \mathrm{Cl}-12.00 \mathrm{PM}-12.05 \mathrm{PM}$ & $<0.05$ \\
\hline $\mathrm{Cl}-24 \mathrm{~h} \& \mathrm{Cl}-1.00 \mathrm{PM}-1.05 \mathrm{PM}$ & $<0.05$ \\
\hline $\mathrm{Cl}-24 \mathrm{~h} \& \mathrm{Cl}-7.00 \mathrm{AM}-1.00 \mathrm{PM}$ & $<0.05$ \\
\hline
\end{tabular}

$\mathrm{Cl}$ - coefficient of irregularity, $p<0.05$ statistically significant, *Only the results for Friedman's test and multiple comparisons for $24 \mathrm{~h}$ and shorter recordings are presented. 
Michal Chudzik, Iwona Cygankiewicz, Artur Klimczak, Joanna Lewek, Karol Bartczak, Jerzy K. Wranicz

Table VI. Correlation between 24-hour data and other examined periods in mean heart rate interval

\begin{tabular}{|c|c|c|}
\hline Variables & $R$ & Value of $p$ \\
\hline Mean HR - 24 h \& Mean HR - 8.00 AM - 9.00 AM & 0.6660 & $<0.001$ \\
\hline Mean HR - 24 h \& Mean HR - 9.00 AM - 10.00 AM & 0.5475 & $<0.001$ \\
\hline Mean HR - 24 h \& Mean HR - 10.00 AM - 11.00 AM & 0.5262 & $<0.001$ \\
\hline Mean HR - 24 h \& Mean HR - 11.00 AM - 12.00 PM & 0.7226 & $<0.001$ \\
\hline Mean HR - 24 h \& Mean HR - 12.00 PM - 1.00 PM & 0.7485 & $<0.001$ \\
\hline Mean HR - 24 h \& Mean HR - 1.00 PM - 2.00 PM & 0.7770 & $<0.001$ \\
\hline Mean HR - 24 h \& Mean HR - 8.00 AM - 8.05 AM & 0.6489 & $<0.001$ \\
\hline Mean HR - 24 h \& Mean HR - 9.00 AM - 9.05 AM & 0.5455 & $<0.001$ \\
\hline Mean HR - 24 h \& Mean HR - 10.00 AM - 10.05 AM & 0.3956 & $<0.01$ \\
\hline Mean HR - 24 h \& Mean HR - 11.00 AM - 11.05 AM & 0.6589 & $<0.001$ \\
\hline Mean HR - 24 h \& Mean HR - 12.00 PM - 12.05 PM & 0.6821 & $<0.001$ \\
\hline Mean HR - 24 h \& Mean HR - 1.00 PM - 1.05 PM & 0.6010 & $<0.001$ \\
\hline Mean HR - 24 h \& Mean HR - 7.00 AM - 1.00 PM & 0.7938 & $<0.001$ \\
\hline
\end{tabular}

Mean HR - mean heart rate interval, $R$ - Spearman's rank coefficient of correlation

Table VII. Correlation between 24-hour data and other examined periods in coefficient of irregularity

\begin{tabular}{|c|c|c|}
\hline Variables & $R$ & Value of $p$ \\
\hline $\begin{array}{l}\mathrm{Cl}-24 \mathrm{~h} \& \mathrm{Cl}- \\
8.00 \mathrm{AM}-9.00 \mathrm{AM}\end{array}$ & 0.4846 & $<0.001$ \\
\hline $\begin{array}{l}\mathrm{Cl}-24 \mathrm{~h} \& \mathrm{Cl}- \\
9.00 \mathrm{AM}-10.00 \mathrm{AM}\end{array}$ & 0.4551 & $<0.001$ \\
\hline $\begin{array}{l}\mathrm{Cl}-24 \mathrm{~h} \& \mathrm{Cl}- \\
10.00 \mathrm{AM}-11.00 \mathrm{AM}\end{array}$ & 0.7219 & $<0.001$ \\
\hline $\begin{array}{l}\mathrm{Cl}-24 \mathrm{~h} \& \mathrm{Cl}- \\
11.00 \mathrm{AM}-12.00 \mathrm{PM}\end{array}$ & 0.6322 & $<0.001$ \\
\hline $\begin{array}{l}\mathrm{Cl}-24 \mathrm{~h} \& \mathrm{Cl}- \\
12.00 \mathrm{PM}-1.00 \mathrm{PM}\end{array}$ & 0.5986 & $<0.001$ \\
\hline $\begin{array}{l}\mathrm{Cl}-24 \mathrm{~h} \& \mathrm{Cl}- \\
1.00 \mathrm{PM}-2.00 \mathrm{PM}\end{array}$ & 0.6564 & $<0.001$ \\
\hline $\begin{array}{l}\mathrm{Cl}-24 \mathrm{~h} \& \mathrm{Cl}- \\
8.00 \mathrm{AM}-8.05 \mathrm{AM}\end{array}$ & 0.4811 & $<0.001$ \\
\hline $\begin{array}{l}\mathrm{Cl}-24 \mathrm{~h} \& \mathrm{Cl}- \\
9.00 \mathrm{AM}-9.05 \mathrm{AM}\end{array}$ & 0.3524 & $<0.05$ \\
\hline $\begin{array}{l}\mathrm{Cl}-24 \mathrm{~h} \& \mathrm{Cl}- \\
10.00 \mathrm{AM}-10.05 \mathrm{AM}\end{array}$ & 0.5124 & $<0.001$ \\
\hline $\begin{array}{l}\mathrm{Cl}-24 \mathrm{~h} \& \mathrm{Cl}- \\
11.00 \mathrm{AM}-11.05 \mathrm{AM}\end{array}$ & 0.5509 & $<0.001$ \\
\hline $\begin{array}{l}\mathrm{Cl}-24 \mathrm{~h} \& \mathrm{Cl}- \\
12.00 \mathrm{PM}-12.05 \mathrm{PM}\end{array}$ & 0.6020 & $<0.001$ \\
\hline $\begin{array}{l}\mathrm{Cl}-24 \mathrm{~h} \& \mathrm{Cl}- \\
1.00 \mathrm{PM}-1.05 \mathrm{PM}\end{array}$ & 0.5542 & $<0.001$ \\
\hline $\begin{array}{l}\mathrm{Cl}-24 \mathrm{~h} \& \mathrm{Cl}- \\
7.00 \mathrm{AM}-1.00 \mathrm{PM}\end{array}$ & 0.8336 & $<0.001$ \\
\hline
\end{tabular}

$\mathrm{Cl}$ - coefficient of irregularity, $R$ - Spearman's rank coefficient of correlation

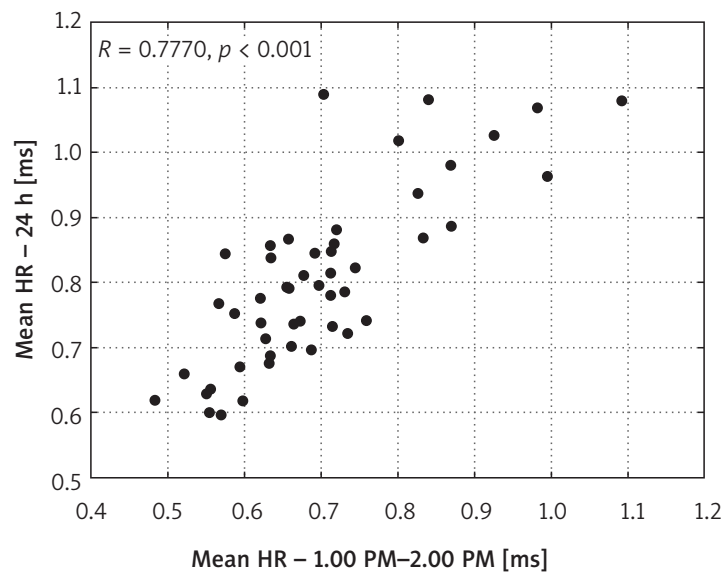

Figure 1. Correlation in mean heart rate interval between 24-hour period and 1.00 PM-2.00 PM in 50 patients with atrial fibrillation

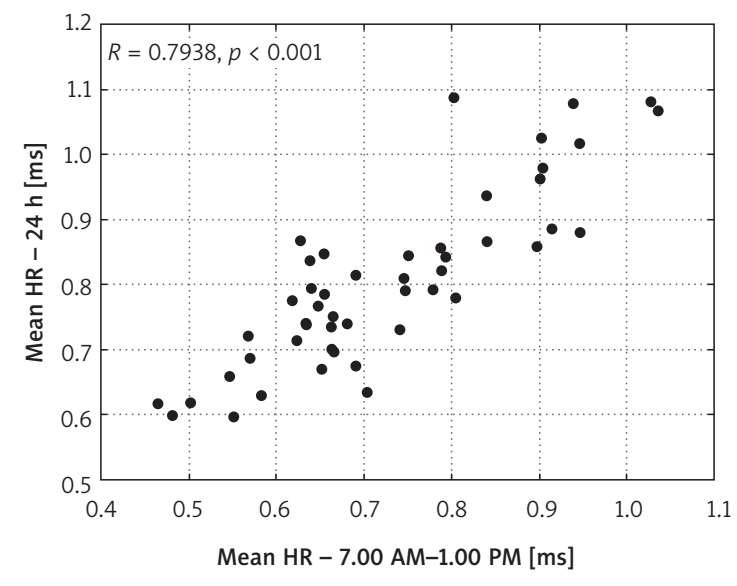

Figure 2. Correlation in mean heart rate interval between 24-hour period and 7.00 AM-1.00 PM in 50 patients with atrial fibrillation 
vals contain data comparable to those obtained from long-term 24-hour ambulatory monitoring. The highest correlation in mean heart rate interval of a 24-hour period with 7.00 AM-1.00 PM, 11.00 AM-12.00 PM and 12.00 PM-1.00 PM was found. Unfortunately, short (5-minute) recordings seem not to be useful in predicting 24-hour parameters in patients with AFib. The coefficient of variation also seems to be a non-predictive parameter in 5-minute as well as 60-minute periods compared to standard 24 ECG recordings. To the best of our knowledge, this is the first study to assess both mean heart rate and rate irregularity from short-term (5 $\mathrm{min}$ and $60 \mathrm{~min}$ ) recordings as compared to long-term 24-hour Holter monitoring.

The adequate control of ventricular rate constitutes an essential aspect of AFib management [6-11]. However, no consensus on how to define proper control exists. Evidence-based data to guide clinicians are in short supply, and many published definitions of rate control are somewhat arbitrary. No strict, widely accepted definition exists. Rapid rates can provoke acute hemodynamic decompensation or aggravation of chronic congestive heart failure symptoms. Inadequate rate control and/or rate irregularity may result in hemodynamic impairment and tachycardia-induced cardiomyopathy [16-18]. On the other hand, no significant correlations between achieved heart rate and clinical outcome, such as survival free from cardiac hospitalization, overall survival, NYHA functional class, 6-minute walking test, and quality of life, were observed [19, 20].

Several methods to assess heart rate, from physical examination with radial pulse assessment or heart apical auscultation to electrocardiography, have been evaluated; however, no consensus exists so far on the length of heart rate estimation [21, 22]. Despite the routine and widespread use of electrocardiography in clinical practice, still the assessment of heart rate in AFib patients remains a challenge. The short period of heart rate recording and difficulty in estimation of RR interval variation are the main drawbacks of surface electrocardiography. It seems that ambulatory 24-hour ECG monitoring is the gold standard for ventricular rate assessment. This method allows for examination of all parameters related to AFib - minimal, maximal, and mean heart rate as well as episodes of tachycardia. In addition, ECG Holter monitoring allows for assessment of variability of ventricular response during AFib, giving an insight into AV node conduction. Unfortunately, from an everyday clinical practice point of view, it is not possible to perform long-term ECG monitoring for rate control assessment in every patient at each follow-up visit. Therefore, it is plausible that short- term recordings could be considered as an alternative approach.

The first study which tried to estimate the shortest sample for heart rate assessment in AFib patients was published by Watt et al. in 1984 [23]. The authors analyzed the RR intervals from 4-minute ECG recordings in supine position and found that average heart rate derived from a 20 -second sample of AFib approximates $( \pm 5 \%)$ the true value in $92.5 \%$ of patients. Additionally, 2-minute samples were required for assessment of the shortest RR interval with a true value in $90 \%$ of patients. With these results as a basis, in 1989, Atwood et al. [24] tried to investigate the ideal sampling interval for the estimation of heart rate at rest and during exercise. In this study, measurements of $\mathrm{HR}$ were obtained at 9 different sampling intervals $(1,2,3,4,5,6,10,15$, and $20 \mathrm{~s})$ at rest and 7 different sampling intervals $(1,2,3,6,10,15$, and $20 \mathrm{~s})$ during last $30 \mathrm{~s}$ of each minute during exercise. The heart rate obtained from each interval was compared with true heart rate - determined by a 4-minute sample at rest and by the last $30 \mathrm{~s}$ of each minute during exercise. Additionally, Atwood et al. concluded that acceptable error in heart rate measurement is not to be defined universally but needs to be addressed individually. The main limitation of this study was the very small number of studied patients - only 10 subjects.

To date, there is no study that can clearly show which is the shortest ECG interval suitable for estimation of mean heart rate.

Our study, to our knowledge, is the first to estimate ECG sample length predictive for heart rate irregularity. A variable RR interval is a hallmark of AFib. Irregularity of the ventricular rate in AFib must be distinguished from "heart rate variability" (HRV) in sinus rhythm. A variable ventricular response in AFib depends on the irregular and chaotic bombardment of the atrioventricular (AV) node from the atria, the complex and sophisticated structure and transmission possibility of the AV node, and autonomic modulation of the AV node $[25,26]$. Ventricular rate irregularity in AFib is an independent factor that can lead to tachycardia-induced cardiomyopathy $[16,17]$. Sometimes, it is impossible to determine whether it is a fast or an irregular rate that causes tachycardiomyopathy $[27,28]$. Therefore, our strategy for the management of ventricular rate should be aimed at these two factors. The coefficient of irregularity, a quotient of standard deviation and $\mathrm{mHR}$ (SD/HR), is an established ventricular irregularity parameter [15]. It could be calculated from Holter monitoring, and it has been used in some clinical studies of patients with AFib $[15,29,30]$. According to Greenhut et al. [15], irregularity of the ventricular rate in AFib was established as significant if 
superior to 0.2. Our group showed that even in patients with $\mathrm{mHR}$ within acceptable limits and no tachycardia episodes on Holter monitoring, irregularity with $\mathrm{Cl}$ greater than 0.2 was found in the majority of the studied population [30].

In contrast to mean heart rate assessment, we were unable to find a short 5-minute or 60-minute sample that would correspond to $\mathrm{Cl}$ determined on 24-hour monitoring. Only the 6-hour sample $\mathrm{Cl}$ obtained between 7.00 AM and 1.00 PM yielded results comparable with those retrieved from long-term evaluation. It seems that in patients with AFib, only a long-term period of irregularity recording provides acceptable results which could be predictive for 24-hour monitoring.

For mean $\mathrm{HR}$ as well as for $\mathrm{Cl}$, the longest recording time shows the highest correlation with standard 24-hour recording. It seems that the "golden hour" for mean HR and rate irregularity assessment is still a great challenge for our clinical practice.

In conclusion, only long-term (6-hour) recordings provide a high correlation with 24 -hour data in mean heart rate interval and coefficient of irregularity. It seems that mean heart rate interval in the 1-hour period between 11.00 AM and 2.00 PM might be predictable for 24-hour data. Short time recordings of the coefficient of irregularity of heart rate in AFib patients at this moment are not useful in clinical practice for long-term prognosis of ventricular irregularity.

\section{References}

1. Luderitz B, Jung W. Quality of life in patients with atrial fibrillation. Arch Intern Med 2000; 160: 1749-57.

2. Thrall G, Lane D, Carroll D, Lip GY. Quality of life in patients with atrial fibrillation: a systematic review. Am J Med 2006; 119: 448.e1-19.

3. Melenowsky V, Hay I, Fetics BJ. Functional impact of rate irregularity in patients with heart failure and atrial fibrillation receiving cardiac resynchronization therapy. Eur Heart J 2005; 26: 705-11.

4. Dandamudi G, Rampurwala AY, Mahenthiran J, Miller JM, Das MK. Persistent left ventricular dilatation in tachycardia-induced cardiomyopathy patients after appropriate treatment and normalization of ejection fraction. Heart Rhythm 2008; 8: 1111-4.

5. Gopinathannair R, Sullivan R, Olshansky B. Tachycardia-mediated cardiomyopathy: recognition and management. Curr Heart Fail Rep 2009; 6: 257-64.

6. Jeong YH, Choi KJ, Song JM, et al. Diagnostic approach and treatment strategy in tachycardia-induced cardiomyopathy. Clin Cardiol 2008; 31: 172-8.

7. Hohnloser SH, Kuck KH, Lilienthal J; the PIAF investigators. Rhythm or rate control in atrial fibrillation - Pharmacological Intervention in Atrial Fibrillation (PIAF): a randomised trial. Lancet 2000; 356: 1789-94.

8. Carlsson J, Miketic S, Windeler J, et al.; the STAF investigators. Randomized trial of rate-control versus rhytm control in persistent atrial fibrillation. The strategies of treatment on atrial fibrillation (STAF) study. Am Coll Cardiol 2003; 41: 1690-1.
9. Galder IC, Hagens VE, Bosker HA, et al.; the Rate Control versus Electrical Cardioversion for Persistent Atrial Fibrillation Study Group. A comparison of rate control and rhythm control in patients with recurrent persistent atrial fibrillation. N Engl J Med 2002; 347: 1834-40.

10. Wyse DG, Waldo AL, DiMarco JP, et al.; the the AFFIRM investigators. A comparison of rate control and rhythm control in patients with atrial fibrillation. N Engl J Med 2002; 347: 1825-33.

11. Olshansky B, Rosenfeld LE, Warner AL, et al. The atriall fibrillation follow up investigation of rhythm management (AFFIRM) study. Approaches to control rate in atrial fibrillation. J Am Coll Cardiol 2004; 43: 1201-8.

12. Fuster V, Ryden LE, Cannom DS, et al. ACC/AHA/ESC 2006 guidelines for the management of patients with atrial fibrillation: full text: a report of the American College of Cardiology/American Heart Association Task Force on practice guidelines and the European Society of Cardiology Committee for Practice Guidelines (Writing Committee to Revise the 2001 guidelines for the management of patients with atrial fibrillation) developed in collaboration with the European Heart Rhythm Association and the Heart Rhythm Society. Europace 2006; 8: 651-745.

13. McBride D, Mattenklotz AM, Willich SN, Brüggenjürgen B. The costs of care in atrial fibrillation and the effect of treatment modalities in Germany. Value Health 2009; 12: 293-301.

14. Naccarelli GV, Johnston SS, Lin J, Patel PP, Schulman KL. Cost burden of cardiovascular hospitalization and mortality in ATHENA-like patients with atrial fibrillation/ atrial flutter in the United States. Clin Cardiol 2010; 33: 270-9.

15. Greenhut SE, Fraser J, Steinhaus B, Feld G, Hughes W. Optimized standby rate reduces the ventricular rate variability in pacemaker patients with atrial fibrillation. Pacing Clin Electrophysiol 1996; 19: 1780-5.

16. Stein KM, Borer JS, Hochreiter C, Devereux RB, Kligfield P. Variability of the ventricular response in atrial fibrillation and prognosis in chronic nonischemic mitral regurgitation. Am J Cardiol 1994; 74: 906-1111.

17. Clark DM, Plumb VJ, Epstein AE, Kay GN. Hemodynamic effects of an irregular sequence of ventricular cycle lengths during atrial fibrillation. J Am Coll Cardiol 1997; 30: 1039-45.

18. Naito M, David D, Michelson EL. The hemodynamic consequence of cardiac arrhythmias: evaluation of the relative roles of abnormal atrioventricular sequencing, irregularity of ventricular rhythm and atrial fibrillation in a canine model. Am Heart J 1983; 106: 284-91.

19. Okcun B, Yigit Z, Yildiz A. What should be the primary treatment in atrial fibrillation: ventricular rate control or sinus rhythm control with long-term anticoagulation? J Int Med Res 2009; 37: 464-71.

20. Climent AM, Guillem MS, Husser D, Castells F, Millet J, Bollmann A. Role of the atrial rate as a factor modulating ventricular response during atrial fibrillation. Pacing Clin Electrophysiol 2010; 15: 1-8.

21. Hollerbach AD, Sneed NV. Accuracy of radial pulse assessment by length of counting interval. Heart Lung 1990; 19: 258-64.

22. Sneed NV, Hollerbach AD. Accuracy of heart rate assessment in atrial fibrillation. Heart Lung 1992; 21: 427-33.

23. Watt JH, Donner AP, McKinney CM, Klein GJ. Atrial fibrillation: minimal sampling interval to estimate average rate. J Electrocardiol 1984; 17: 153-6. 
24. Atwood JE, Myers J, Sandhu S, et al. Optimal sampling interval to estimate heart rate at rest and during exercise in atrial fibrillation. Am J Cardiol 1989; 63: 45-8.

25. Wasmund SL, Pai RK, Freedman RA, et al. Modulation of the sinus rate during ventricular fibrillation. J Cardiovasc Electrophysiol 2009; 20: 187-92.

26. Chou CC, Chen PS. New concepts in atrial fibrillation: mechanism and remodeling. Med Clin North Am 2008; 92: 53-63.

27. Ueshima K, Myers J, Ribis PM, et al. Exercise capacity and prognosis in patients with chronic atrial fibrillation. Cardiology 1995; 86: 108-13.

28. Daoud EG, Weiss R, Bahu M. Effect of an irregular ventricular rhythm on cardiac output. Am J Cardiol 1996; 78: 1433-6.

29. Tse HF, Wong KK, Siu CW, et al. Impacts of ventricular rate regularization pacing at right ventricular apical vs. septal sites on left ventricular function and exercise capacity in patients with permanent atrial fibrillation. Europace 2009; 11: 594-600.

30. Chudzik M, Wranicz JK, Cygankiewicz I, Klimczak A, Goch JK. Is mean heart rate a reliable predictor in the pharmacotherapy of patients with atrial fibrillation? Folia Cardiol 2006; 13: 473-9. 